\title{
Protein supplementation combined with low-intensity resistance training in geriatric medical patients during and after hospitalisation: a randomised, double-blind, multicentre trial
}

\author{
Josephine Gade ${ }^{1,2 *}$ (1) , Anne Marie Beck ${ }^{2,3}$, Hanne E. Andersen ${ }^{4}$, Britt Christensen ${ }^{5}$, Finn Rønholt ${ }^{6}$, \\ Tobias W. Klausen ${ }^{7}$, Anders Vinther ${ }^{8}$ and Arne Astrup ${ }^{1}$ \\ ${ }^{1}$ Department of Nutrition, Exercise and Sports, Copenhagen University, 2200 Copenhagen, Denmark \\ ${ }^{2}$ Dietetics and Clinical Nutrition Research Unit, Herlev and Gentofte Hospital, 2730 Herlev, Denmark \\ ${ }^{3}$ University College Copenhagen, Institute for Nursing and Nutrition, Faculty of Health, 2200 Copenhagen, Denmark \\ ${ }^{4}$ Medical Department M, Rigshospitalet-Glostrup, 2600 Glostrup, Denmark \\ ${ }^{5}$ Arla Foods Amba, 8260 Viby, Denmark \\ ${ }^{6}$ Medical Department, Herlev and Gentofte Hospital, 2730 Herlev, Denmark \\ ${ }^{7}$ Department of Haematology, Herlev and Gentofte Hospital, 2730 Herlev, Denmark \\ ${ }^{8}$ Department of Physiotherapy and Occupational Therapy and QD-Research Unit, Herlev and Gentofte Hospital, 2730 Herlev, \\ Denmark
}

(Submitted 6 May 2019 - Final revision received 10 July 2019 - Accepted 15 July 2019)

\section{Abstract}

Sarcopenia (loss of muscle mass/strength) burdens many older adults - hospitalised older adults being particularly vulnerable. Treating the condition, protein supplementation (PrS) and resistance training (RT) may act synergistically. Therefore, this block-randomised, double-blind, multicentre intervention study, recruiting geriatric patients $>70$ years from three medical departments, investigated the effect of PrS combined with RT during hospitalisation and 12 weeks after discharge. Participants were randomly allocated (1:1) to receive PrS (totally $27 \cdot 5 \mathrm{~g}$ whey protein/d, about $2000 \mathrm{~kJ} / \mathrm{d}$ ) or isoenergetic placebo-products ( $<1.5 \mathrm{~g}$ protein/d) divided into two servings per d to supplement the habitual diet. Both groups were engaged in a standardised, progressive low-intensity RT programme for the lower extremities (hospital: supervised daily/ after discharge: self-training 4×/week). From April 2016 to September 2017, 2351 patients were screened, 462 were eligible, and 165 included. Fourteen were excluded and ten dropped out, leaving 141 participants in the intention-to-treat analysis. The average total protein intake during hospitalisation/after discharge was 1.0 (interquartile range (IQR) $0 \cdot 8,1 \cdot 3$ ) $/ 1 \cdot 1$ (IQR 0.9, 1.3) g/ $\mathrm{kg}$ per d (protein-group) and 0.6 (IQR 0.5, 0.8)/0.9 (IQR $0 \cdot 6,1 \cdot 0) \mathrm{g} / \mathrm{kg}$ per d (placebo group). Both groups improved significantly for the primary and secondary endpoints of muscle mass/strength, functional measurements and quality of life, but no additional effect of PrS was seen for the primary endpoint (30-s chair stand test, repetitions, median changes from baseline: (standard test: 0 (IQR 0, 5) (protein group) $v .2$ (IQR 0, 6) (placebo group) and modified test: 2 (IQR 0, 5) (protein group) $v .2$ (IQR -1, 5) (placebo group)) or any secondary endpoints (Mann-Whitney $U$ tests, $P>0 \cdot 05$ ). In conclusion, PrS increasing the total protein intake by 0.4 and $0.2 \mathrm{~g} / \mathrm{kg}$ per d during hospitalisation and after discharge, respectively, does not seem to increase the adaptive response to low-intensity RT in geriatric medical patients.

Key words: Sarcopenia: Older adults: Milk-based protein: Muscle strength: Muscle mass: Physical function: Rehabilitation

Sarcopenia is a progressive, generalised skeletal muscle disorder characterised by the loss of muscle mass/quality and accompanying muscle weakness. When the physical function is also affected, sarcopenia is considered severe ${ }^{(1)}$. Sarcopenia burdens many older adults - prevalence differs widely depending on the methods and definitions used ${ }^{(2)}$, but up to $50 \%$ of older adults $>80$ years are estimated to be affected by it ${ }^{(3)}$. The primary cause of sarcopenia is age related, while secondary causes are disease, nutrition or activity related ${ }^{(3,4)}$. Only recently sarcopenia has been recognised as an independent condition/ disease, by receiving its own International Classification of Disease, Tenth Revision, Clinical Modification (ICD-10-MC)

Abbreviations: BIA, bio-impedance analysis; CST, chair stand test; EWGSOP2, European Working Group on Sarcopenia in Older People; IQR, interquartile range; LBM, lean body mass; mITT, missing intention to treat; MMSE, the Mini Mental State Examination; MPS, muscle protein synthesis; NRS, nutritional risk screening; $\mathrm{PP}$, per-protocol; PrS, protein supplementation; RT, resistance training; VAS, visual analogue scale.

* Corresponding author: J. Gade, email josephine.gade.bang-petersen@regionh.dk 
Table 1. Eligibility criteria for study participation

\begin{tabular}{ll}
\hline Inclusion criteria & Exclusion criteria \\
\hline Female or male & Active cancer or terminal disease \\
Age $\geq 70$ years & Renal insufficiency* \\
Speak/understand Danish & Cognitive impairment $\dagger$ \\
Expected length of stay $>3 \mathrm{~d} \ddagger$ & Enteral or parenteral nutrition only \\
Independent stand function $>30 \mathrm{~s}$ & Milk/lactose allergy/ intolerance \\
& Plan of losing weight/special diet \\
& Pacemaker§
\end{tabular}

* Estimated glomerular filtration rate $<30 \mathrm{ml} / \mathrm{min}$ per $1.73 \mathrm{~m}^{2}$.

† Not able to comprehend the purpose of the study/give informed consent.

‡ Evaluated by the medical staff at the department.

$\S$ Due to bio-impedance analysis measurements.

code ${ }^{(5)}$. The most recent consensus definition of sarcopenia focuses on muscle strength as the key characteristic of sarcopenia to be used in the identification of people with the disease, while measures of muscle mass/quality can be used confirmatively $^{(1)}$. Sarcopenia increases the risk of disability, morbidity, hospitalisation and mortality ${ }^{(1,3,6-8)}$ and is associated with decreased quality of life $\mathrm{e}^{(9)}$ as well as increased healthcare $\operatorname{costs}^{(6,10)}$. Thus, identification of effective strategies to prevent or counteract sarcopenia is highly relevant - especially in geriatric patients who are particularly vulnerable, as they are likely to be subject to all secondary causes of sarcopenia.

It has been shown that protein supplementation $(\mathrm{PrS})$ alone can improve parameters of muscle strength, muscle mass and physical function in older adults ${ }^{(11-13)}$. Also, PrS has been shown to enhance the adaptive response to resistance training (RT) interventions (mostly 6-12 weeks' duration); however, not in all studies ${ }^{(11,14-23)}$. A hypothesis is that those who are most weak, for example, frail and sarcopenic, or those having a low habitual protein intake might benefit more from a combined intervention of $\operatorname{PrS}$ and $\mathrm{RT}^{(11,13-16,19,22,24-26)}$. Despite this, the evidence is sparse in geriatric patients, many of whom are weak and malnourished and with higher metabolic demands due to acute and/or chronic inflammatory conditions ${ }^{(25)}$. Thus, the aim of the present study was to investigate whether PrS has any additional effects in a population of Danish geriatric medical patients engaged in RT during hospitalisation and 12 weeks after discharge, on parameters of muscle strength, muscle mass and physical and mental function.

\section{Subjects and methods}

\section{Ethics statement}

The study was conducted in accordance with the principles of the World Medical Association Declaration of Helsinki. Approval was given by the Research Ethic Committee of the Capital Region of Denmark (H-16018240), the Danish Data Protection Agency (HGH-2016-050), and the study is registered and available in the clinical.trial.gov database (NCT02717819, registered 9 March 2016). Furthermore, a study protocol has been published, verifying adherence to original intent ${ }^{(27)}$. Participants did not have any cost associated with participation, and informed consent was signed before enrolment.

\section{Study design and population}

The study was a block-randomised, double-blinded, placebocontrolled, multicentre intervention study. Patients were screened consecutively by study investigators from three Medical Departments of three different Hospitals in the Capital Region of Denmark (Herlev, Gentofte, and Glostrup Hospital). Recruitment took place within $72 \mathrm{~h}$ of admission. After inclusion and baseline tests, participants were randomly allocated (1:1) to receive either PrS or an isoenergetic placebo product, to supplement habitual diet. Randomisation was performed in blocks of 20 , according to the recruitment site, using sealed, opaque envelopes containing papers with either an 'A' or a 'B'. Participants, hospital staff and study investigators were blinded towards the randomisation. Both groups followed the same RT programme and took daily vitamin D supplements. The intervention started at the hospital after randomisation and lasted until 12 weeks after discharge. All patients admitted to one of the three recruitment sites, without planned transfer to other hospitals/departments, were considered for the study. The eligibility criteria are summarised in Table 1 . The published study protocol can be referred to for more details about the methods ${ }^{(27)}$.

\section{Intervention}

Intervention products. Participants allocated to the protein group received a protein-enriched, milk-based supplement (Protino, Arla Foods ${ }^{\circledR}: 2120 \mathrm{~kJ}, 27.5 \mathrm{~g}$ protein (25 g whey/ $2.5 \mathrm{~g}$ casein), $27.5 \mathrm{~g}$ fat, $37.5 \mathrm{~g}$ carbohydrate and $2.8 \mu \mathrm{g}$ vitamin D per $250 \mathrm{ml}$ ) (refer to the published study protocol, online Supplementary Table S1 in Gade et $a l .{ }^{(27)}$, for amino acid profile of the intervention product). Participants allocated to the placebo group received an isoenergetic placebo beverage (Arla Foods ${ }^{\circledR}: 2108 \mathrm{~kJ}, 1.5 \mathrm{~g}$ protein, $26.9 \mathrm{~g}$ fat, $63.9 \mathrm{~g}$ carbohydrate per $250 \mathrm{ml}$ ) developed specifically for the present study. Both products were ready to drink, with a flavour of raspberry, and came in white bottles with either an 'A' or ' $\mathrm{B}$ ' label on the front. Participants were instructed to drink $250 \mathrm{ml}$ intervention product per d divided into two servings, leading to a total daily dose of $27.5 \mathrm{~g}$ protein in the protein group $v$. about $1.5 \mathrm{~g}$ protein in the placebo group. While hospitalised, the participants had the supplements served at breakfast and after the RT, mostly in the afternoon. After discharge, participants were advised to have one serving at breakfast and one serving with the next cold main meal. However, consumption at any time was preferred over not drinking the supplements because of specific timing constrictions. The participants were told to continue with their habitual dietary intake, unless they were advised otherwise by health care providers. Furthermore, to ensure comparable intakes between groups, all participants were provided with and instructed to take a daily vitamin D supplement of $20 \mu \mathrm{g}$, as recommended by the Danish National Board of Health ${ }^{(28)}$. An exception was whether the serum levels at baseline were $\geq 100 \mathrm{nmol} / \mathrm{l}$ or when higher doses were prescribed. During hospital admission, the vitamin $\mathrm{D}$ was handed out by nurses or study investigators. Participants who consented had a daily text message reminding them about study compliance.

Resistance exercise training programme. The RT programme consisted of three exercises targeting the gluteal, quadriceps, 
hamstring and calf muscles. The exercises were a bridging exercise, a chair rise exercise and a heel raise exercise. A training session consisted of three sets of each exercise, aiming for ten repetitions, pursuing an intensity of 8-12 repetitions maximum. The RT programme was adjusted after standardised procedures to ensure progression (regression, if necessary). The exercises existed in five different modes (A-B-C-D-E), graduated in terms of increasing resistance, by applying the participants' own body weight and different starting positions (refer to the published study protocol, online Supplementary Fig. S1 in Gade et al. ${ }^{(27)}$, for illustrated exercises). Daily supervised RT was offered in addition to the standard care during hospital admission. After discharge, the participants were encouraged to perform the same RT programme four times per week as home-based self-training. Furthermore, the participants received home visits by a physiotherapist in study weeks 3, 6 and 9 and after discharge if readmitted. During these visits, the RT programme was supervised and adjusted if needed.

Measures of compliance. During hospitalisation, the study investigators and physiotherapists registered compliance to the supplements, vitamin D and amount of RT performed (number of sets and repetitions for each exercise and days with no RT). After discharge, the participants were instructed to save all bottles of the intervention product, both empty and full if non-compliant. The bottles were picked up during home visits and simultaneously new supplies were also delivered. For those participants discharged to a 24-h rehabilitation centre, an agreement with the relevant staff was made, who handed out the supplements and saved all bottles. Originally, participants were instructed to register compliance (RT/intervention products/vitamin $\mathrm{D})$ in a 'study diary', but for the vast majority ( $>95 \%$ ) this was too high a burden/workload for them to handle. Thus, this strategy was abandoned, and it was made optional. Subsequently, compliance with the RT and vitamin D was registered as detailed as possible during the weekly phone call to participants, asking about the overall compliance and any deviations. The average RT compliance was categorised into one of five ordinal 'activity categories' (for definition of the categories refer to the online Supplementary Table S1). Regarding vitamin D intake, if handed out (some participants took vitamin D as part of a multivitamin tablet), the number of tablets left in the bottle was counted at the last visit. Also, the content labels of the participants' medicine/vitamin bottles were checked at home visits to ensure participants did not receive too high amounts, or to register the total intake for those participants prescribed higher amounts.

\section{Outcome parameters}

Baseline characteristics and endpoints were collected/measured prior to randomisation and within $72 \mathrm{~h}$ of admission to the medical department. Endpoints were measured again within $72 \mathrm{~h}$ after discharge (at the hospital or at home) and after 12 weeks ( $\pm 2 \mathrm{~d}$ ) (at home). Tests were performed in a predefined order to reduce fatigue and 1.5-2 $\mathrm{h}$ after breakfast (sometimes $1.5-2 \mathrm{~h}$ after lunch). Follow-up registration of admission to hospital, length of stay(s) and mortality was made for 6 months after the intervention period. All data were collected by study investigators and followed standardised procedures.
Baseline characteristics. Besides different participant characteristics collected from the participants and the electronic patient register, participants were screened for depression using the Geriatric Depression Scale ${ }^{(29)}$, screened for nutritional risk according to nutritional risk screening (NRS-2002) ${ }^{(30)}$ and categorised into 'no sarcopenia, sarcopenia and severe sarcopenia', according to the revised definition from the European Working Group on Sarcopenia in Older People (EWGSOP2) (using proposed cut-off points for handgrip strength, appendicular skeletal muscle mass index and gait speed $)^{(1)}$.

Primary endpoint. The 30-s chair stand test (30-s CST) is used to measure muscle strength in the lower extremities, measured using both a standardised and modified version ${ }^{(31,32)}$. The number of times the participant could fully rise and sit from a standard chair (height of $43-45 \mathrm{~cm}$ ) in $30 \mathrm{~s}$ was counted, starting from a sitting position. In the standard version, it was done with the arms folded across the chest, while in the modified version the use of the armrests was allowed. Participants who could not stand from the chair without using the arm rest got a score of zero in the standardised version. Those participants only able to perform the modified version at baseline, continued with that for the following assessments; and if they were able to do the standardised version as well, it was performed after minimum 15 min of rest.

Secondary endpoints. Body composition variables were measured in $\mathrm{kg}$ for lean body mass (LBM) (total, arms, legs and trunk), as a measure of skeletal muscle mass, as well as for total fat mass. They were assessed by bio-impedance analysis (BIA) (dual frequency $(20 \mathrm{kHz}, 100 \mathrm{kHz})$, tetra polar 8-Point Tactile Electrode System (InBody-230)). Participants were wearing light clothes and no shoes and were instructed to stand upright with the feet on the build-in electrodes embedded in the scale platform, to grasp the handles of the analyser while spreading the arms as much as possible and to look straight ahead. Test-retest reliability of the BIA for total LBM was 98.4 (95\% CI 96.4, 99.6) \% (intra-class correlation coefficient 0.992 (95\% CI 0.988, 0.995) (two-way mixed, absolute agreement method)), assessed in the study population (duplicate measurements with repositioning, $n$ 93).

$B M I\left(\mathrm{~kg} / \mathrm{m}^{2}\right)$ was calculated using the body weight measured by the BIA equipment and the height of participants measured at baseline with a stadiometer.

Handgrip strength was measured in kilogram with a DHD-1 digital hand dynamometer (Saehan Medical, 2012), using the second handle position. The procedure recommended by Roberts et $a l .{ }^{(33)}$ was used. Participants were asked to perform three maximum force trials with their dominant hand, with 15$\mathrm{s}$ rest in between, and the highest value was registered.

Four-meter gait speed was used to assess the usual gait speed $(\mathrm{m} / \mathrm{s})$ over a short distance. The participants could use a gait aid, which was registered, and the fastest of the two attempts was recorded.

Daily functional ability was assessed by the Barthel-Index (Barthel-100, modified) $^{(34,35)}$, which contains ten measures of everyday and mobility activities scored by observation and clarifying questions. A total of 100 points can be achieved, which reflects full independence.

Mobility was assessed by De Morton Mobility Index, which provides a fifteen-item unidimensional measure of mobility 
across the spectrum from bed bound to independent mobility. A score from 0 to 100 can be achieved, where 100 represents independent mobility ${ }^{(36)}$.

Cognitive functioning was assessed using the Danish version of the Mini Mental State Examination (MMSE) questionnaire (retroactive permission was obtained from Psychological Assessment Resources ). It consists of small simple tasks to elucidate eight different cognitive functions. A score from 0 to 30 can be achieved, where 30 represents the best/optimal function $^{(37)}$.

Health-related quality of life was assessed using the generic questionnaire, Euroqol EQ-5D-3L, which gives an index score as well a visual analogue scale (VAS) ${ }^{(38)}$ score. Prior permission was obtained from the EuroQol Research Foundation.

Social support was evaluated asking participants about the use of home care (yes/no, if yes, then divided into practical help, personal care and both) and residence.

Use of gait aid was registered as yes (including specific gait aid), no or cannot walk.

Admission to hospital and mortality was registered from the electronic patient register. Admission to hospital was registered regarding both the frequency and the total length of the hospital stay(s).

\section{Other measures}

Protein and energy intake and the habitual physical activity are potential confounders. As such, these factors were measured in conjunction with the study intervention as described below. Additionally, the intervention products were evaluated by participants.

Protein and energy intake. During hospitalisation, protein (total $\mathrm{g} / \mathrm{d}$ and $\mathrm{g} / \mathrm{kg}$ per $\mathrm{d}$ ) and energy $(\mathrm{kJ} / \mathrm{d}$ ) intake was registered for up to $4 \mathrm{~d}$ depending on the length of stay. Registration of food and drinks was done by study investigators with help from the participants and nurses. For the period after discharge, protein and energy intake was estimated based on an average of four 24-h dietary recall interviews ${ }^{(39)}$ performed at home visits in study week 3, 6,9 and 12 after discharge. A checklist of specific food and beverages was used to verify the reported intake, and picture series of portion sizes was used to estimate portion sizes ${ }^{(40)}$. For those participants who continued passively in the study, allowing the final assessment, the 24-hour dietary recall interviews (except for the final interview) were done by phone and not during home visits. The software program Madlog Vita ${ }^{\circledR}$ was used to estimate the total intake.

Habitual physical activity. A semi-structured interview was used to assess the participants' general activity levels (daily activities + exercise related) besides the RT programme, dividing them into predefined ordinal categories from one to five,

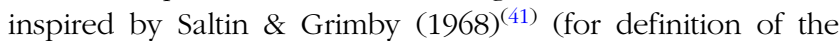
categories refer to online Supplementary Table S1). A total of four interviews were performed in conjunction with the assessment of protein and energy intake.
Product evaluation questionnaire. All participants evaluated the intervention products at the final assessment or earlier if dropping out of the study. Questions were directed towards both liking of the product and possible side effects, even though none was expected.

\section{Statistics}

Power calculation. The power calculation was based on the primary endpoint, the 30-s CST. To detect a clinical relevant difference of $2 \cdot 0$ number of stands ${ }^{(42)}$ between groups, with an SD of 3.31 stands $^{(31)}(\beta=80 \%$ and $\alpha=0.05$, two sided $)$, eighty participants was required in each group, given an anticipated dropout rate of $30 \%{ }^{(43,44)}$ and $15 \%$ non-compliance. The additional $15 \%$ was added to maintain statistical power in the per-protocol (PP) analysis. For practical reasons, inclusion of 165 participants was chosen (fifty-five from each site).

Statistical tests. The primary analysis was performed by the intention-to-treat (ITT) principle, including everyone in the group they were allocated to irrespective of study compliance, but modified such that dropouts and those excluded after randomisation were omitted from the analysis (no imputation techniques for missing data, referred to as MITT in the following text). Secondary analyses were also performed, including PP analysis in those with high compliance only (defined in the present study as an average intake $\geq 75 \%$ of the intervention products, irrespective of the RT compliance) as well as the two sub-group analyses with participants at nutritional risk and sarcopenic participants, respectively. All analyses and tests were performed according to a predefined data analysis plan ${ }^{(27)}$. The groups were primarily compared looking at changes from baseline for the entire intervention period but secondarily also looking separately at changes during the period of hospitalisation (from baseline assessments to discharge) and the 12-week period after discharge. Distribution of the variables (parametric or nonparametric) was determined from kurtosis and skewness [-1:1], Shapiro-Wilk test $>0.05$ and visual inspection of QQ plots. According to distribution, continuous variables are presented as medians and interquartile ranges (IQR) or as means and standard deviations or $95 \% \mathrm{CI}$, and categorical variables as numbers (absolute frequencies) and percentages. Statistical comparisons were made between groups using the Mann-Whitney $U$ test (non-parametric distributions) or Student's $t$ test (parametric distributions) for continuous variables, and the $\chi^{2}$ test or Fisher's exact test (in case of expected cell count $<5$ ) for the comparison of categorical variables. Mann-Whitney $U$ test was used for comparison of ordinal variables. ANCOVA was used to compare continuous, normally distributed outcomes between groups, adjusting for confounding factors (baseline value, amount of training during admission, length of hospital stay, total activity for the period 12 weeks after discharge (not included when looking at the hospitalisation period), energy $(\mathrm{kJ} / \mathrm{d})$ and protein (g/d) from diet (adjusted to the specific time periods). Sensitivity analysis, without outliers and with imputation techniques for missing values, was part of the original data plan but not considered appropriate/necessary, due to no obvious incorrectness of outliers and a low number of missing values. All tests were two tailed, and an $\alpha$ level of $P<0.05$ was used to determine statistical 


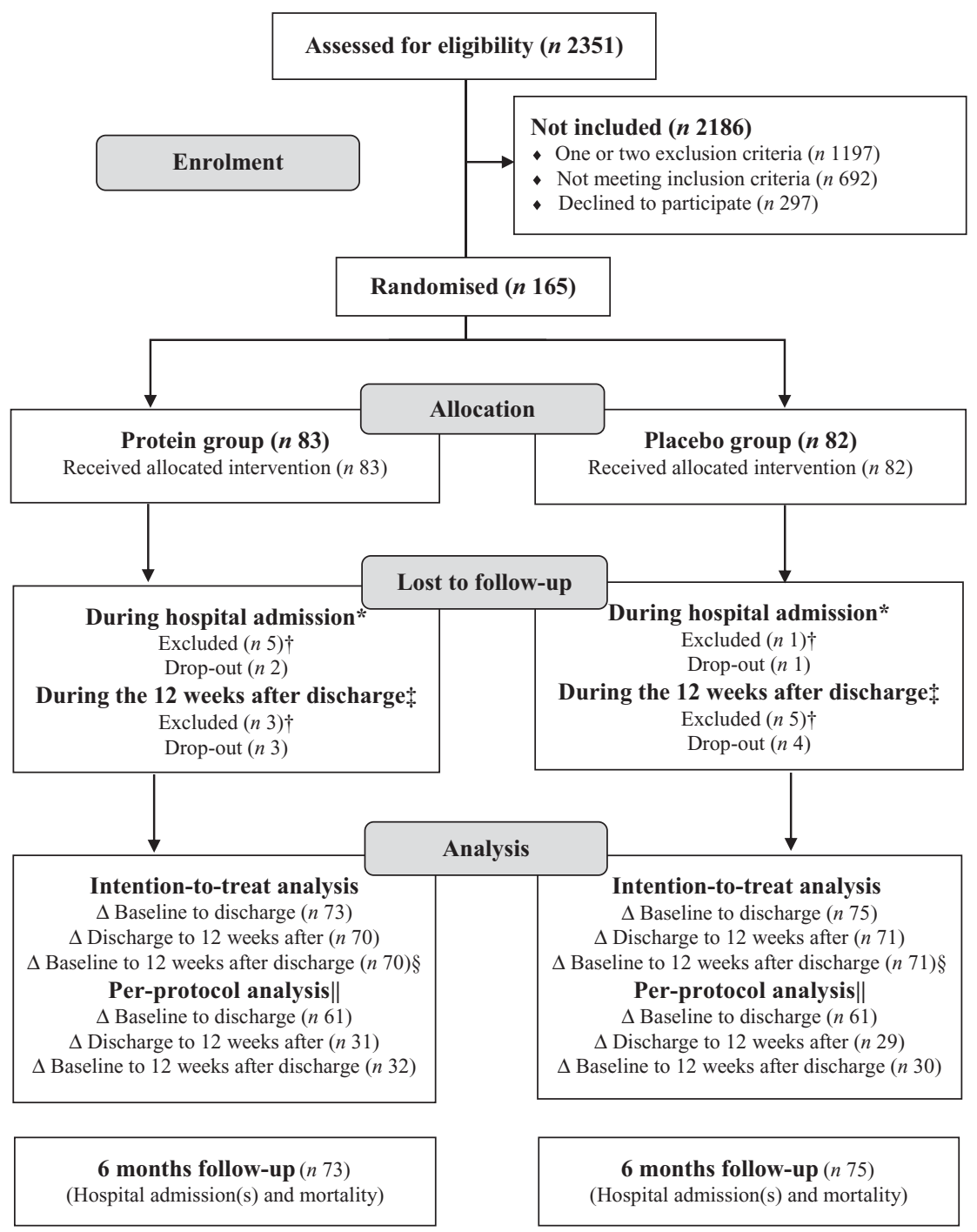

Fig. 1. Participant flow chart. * Reasons for exclusion ( $n$ (protein group/placebo group): moved to another hospital/department or unusual course of disease with infection $(n 3 / 1)$, dead during hospitalisation ( $n 1 / 0)$, delirium $(n 1 / 0)$. Reasons for drop-out ( $n$ (protein group/placebo group): no energy/capacity to continue $(n 2 / 1)$. $\dagger$ Excluded from all analyses. $¥$ Reasons for exclusion ( $n$ (protein group/placebo group): cancer ( $n 3 / 5)$. Reasons for drop-out ( $n$ (protein group/placebo group): no energy/capacity to continue $(n 2 / 0)$, no reasons given $(n 1 / 3)$ and pain $(n 0 / 1)$. $\S$ The primary analysis covering the entire intervention period. II Includes only participants who were highly compliant (consumption of $\geq 75 \%$ of the total dose of intervention product). $\Delta$ : Indicates analysis of changes.

significance. All statistical analyses were performed using SPSS Statistics v22 (SPSS Inc.).

\section{Results}

Recruitment lasted from 25 April 2016 to 11 September 2017, with overlapping periods between sites. The last follow-up data were collected on 15 June 2018. In total, 2351 patients were screened, 462 met the eligibility criteria and 165 accepted to participate. The flow of participants is illustrated in Fig. 1. Due to slower recruitment rate than expected at some sites, the original idea of an even distribution of participants from each site was discarded and instead focus was on reaching the desired total number of participants. A total of fourteen (8.5\%) participants were excluded, primarily due to new cancer diagnosis. Only five
(6\%) participants in each group dropped out, primarily due to medical/personal reasons unrelated to the study or due to the heavy burden of the study intervention, primarily the RT. However, some participants became inactive at some point during the time of the intervention, but accepted the final assessments, so they could be included in the mITT analysis. Three of the dropouts withdrew during the hospitalisation period and thus are not included in any of the analyses, but the other seven dropouts are included in the analysis comparing the groups during the hospitalisation period.

Baseline characteristics are presented in Table 2, and additional characteristics are available in the online Supplementary Table S2. For the mITT analysis, the groups were comparable at baseline for all measured characteristics and endpoints. Also, for the PP analysis, including only those with a high compliance (average intake $\geq 75 \%$ of the intervention products for 
the total intervention period; protein group: $n 32 v$. placebo group: $n$ 30), the groups were comparable at baseline (results not shown). The median duration of the study intervention was similar between the groups for the mITT analysis (length of hospitalisation: protein group: 5 (IQR 4, 8) d and placebo group: 5 (IQR 3, 8) d, and the entire intervention period: protein group: $89 \cdot 5$ (IQR 87, 92) d and placebo group: 89 (IQR 87, 92) d) as well as for the groups in the PP analysis.

\section{Compliance with intervention}

Intervention products. The average compliance (intake in percentage of total dosage) with the intervention products during hospitalisation and following discharge was 87 (SD 19) \% and 62 (SD 32) \% in the protein group and 88 (SD 18) \% and 55 (SD 41) \% in the placebo group, respectively. Subsequently, for the whole intervention period the average compliance was 63 (sD 30) \% and 57 (sD 39) \% in the protein and placebo groups, respectively. During hospitalisation, $84 \%(n 61)$ in the protein group and $81 \%(n 61)$ in the placebo group were highly compliant (intake $\geq 75 \%$ of the total dose). Following discharge, this dropped to $44 \%(n$ 31) and $41 \%(n$ 29) in the protein and placebo groups, respectively. Thus, considering the entire intervention period, $46 \%$ ( $n$ 32) of the protein group and $42 \%$ ( $n$ 30) of the placebo group were categorised as highly compliant. Compliance between groups was not statistically different.

No side effects were observed after consuming the intervention products or after the RT. Some participants did in general experience some discomfort, but this was highly correlated to their acute condition or co-morbidities. Evaluation of the intervention products at the end of the intervention period revealed 38 and $19 \%$ in the protein and placebo groups, respectively, though the products were highly or extremely satiating ( $n$ 135, $P=0 \cdot 016)$. In general, the study products were liked by the participants, and $54 \%$ in the protein group and $47 \%$ in the placebo group rated the liking as 'a lot' or 'very much' ( $n$ 134, $P>0.05$ ). However, 38 and $48 \%$ in the protein and placebo groups, respectively, experienced taste fatigue during the intervention period, of which 16 and $14 \%$ rated it as 'often' or 'very often' (n 133, $P>0 \cdot 05$ ).

Resistance training programme. During hospitalisation, there were no differences in RT compliance or days with RT between groups, and participants were almost fully compliant (Table 3). Likewise, after discharge, no differences between groups were observed for either the amount of home-based RT or other physical activities. About $51 \%$ in both groups followed the RT programme to a moderate to a high degree (Table 3 ). The same picture was seen when looking only at those with a high compliance to the intervention products in the PP analysis (results not shown).

\section{Average protein and energy intake}

The average intake of protein ( $\mathrm{g} / \mathrm{d}$ and $\mathrm{g} / \mathrm{kg}$ per $\mathrm{d}$ ) and energy $(\mathrm{kJ} / \mathrm{d})$ in the two groups is shown in Table 4 . The amounts are shown separately for dietary intake and intervention products as well as a pooled total estimate, and intake is illustrated separately for the period during hospital admission and the 12-week period after discharge. No statistically significant differences were observed between the groups for the dietary intakes. Compared with the placebo group, the protein group had significantly higher protein intake from the intervention products, resulting in significantly higher total protein intake during hospitalisation and after discharge. Regarding energy intake from the intervention products, the protein group had a significantly higher energy intake during hospitalisation (however, only $0.02 \%$ ), but the energy intake from the intervention products after discharge was similar between groups. Regarding the total energy intake, this was not statistically different between groups during hospitalisation or after discharge.

\section{Primary endpoint}

The results of the mITT analysis, for the primary endpoint 30-s CST, are shown in Table 5 . The only statistically significant differences between the groups were for the 12-week period after discharge, where more participants in the placebo group improved $(P=0.042)$ and less had 'no change' in progression $(P=0.023)$, and these were calculated with $\chi^{2}$ tests. For the entire study period there was a tendency of more participants in the placebo group with 'no change' in progression $(P=0 \cdot 056)$. However, considering the results for progression (improve, no change or decline) as an ordinal variable, and analysing data with the Mann-Whitney $U$ test, all $P$ values for the three time periods were non-significant. In the PP analysis, only tendencies were found for progression $\left(\chi^{2}\right.$ tests) (online Supplementary Table S3). The protein group tended to have more participants with improvement in the period of hospitalisation (protein group: $71.7 \% v$. placebo group: $55.7 \%, P=0.069$ ), but the placebo group tended to have more participants with improvements in the period 12 weeks after discharge (protein group: $62 \cdot 1 \% v$. placebo group: $82 \cdot 8 \%, P=0 \cdot 078$ ). Looking at the entire intervention period, more participants in the placebo group tended to experience a decline in the 30-s CST (protein group: $3 \cdot 2 \% v$. placebo group: $17 \cdot 2 \%, P=0 \cdot 053$ ).

\section{Secondary endpoints}

The results of the mITT analysis for the secondary endpoints are shown in Table 6. Looking at the period during hospitalisation, no significant differences were observed between groups, but there was a tendency to an increased Barthel score for the placebo group $(P=0.052)$. During the 12 -week period after discharge, the placebo group had significantly higher improvements in handgrip strength compared with the protein group $(P=0 \cdot 026)$. For the entire intervention period, no significant differences were observed between the groups for any endpoint, but there was a tendency to an increased Barthel score $(P=0.097)$ and improved $4-\mathrm{m}$ gait speed $(P=0.069)$ in the placebo group. In general, both groups improved for most endpoints when considering the total intervention period.

In the PP analysis (online Supplementary Table S2), no differences were found between groups for the hospitalisation period. The only difference between groups for the 12 -week period after discharge was a significantly higher increase in $\mathrm{BMI}$ in the placebo group (median, protein group: 
Table 2. Baseline characteristics by treatment group*

(Numbers and percentages; mean values and standard deviations; medians and interquartile ranges (Q1, Q3))

\begin{tabular}{|c|c|c|c|c|c|c|}
\hline & \multicolumn{2}{|c|}{ Protein } & \multicolumn{2}{|c|}{ Placebo } & \multirow[b]{2}{*}{ Protein $n /$ placebo $n$} & \multirow[b]{2}{*}{$P$} \\
\hline & $n$ & $\%$ & $n$ & $\%$ & & \\
\hline Number of females & 51 & 69.9 & 49 & $65 \cdot 3$ & $73 / 75$ & 0.556 \\
\hline Number of males & 22 & $30 \cdot 1$ & 26 & 34.7 & & \\
\hline Age (years) & & & & & $73 / 75$ & 0.280 \\
\hline Mean & \multicolumn{2}{|c|}{$85 \cdot 3$} & \multicolumn{2}{|c|}{$84 \cdot 2$} & & \\
\hline SD & \multirow{2}{*}{\multicolumn{2}{|c|}{$6 \cdot 2$}} & \multicolumn{2}{|c|}{$6 \cdot 3$} & & \\
\hline BMI $\left(\mathrm{kg} / \mathrm{m}^{2}\right)$ & & & & & $73 / 75$ & 0.393 \\
\hline Mean & \multicolumn{2}{|c|}{$25 \cdot 1$} & \multicolumn{2}{|c|}{$25 \cdot 8$} & & \\
\hline SD & \multicolumn{2}{|c|}{4.2} & \multicolumn{2}{|c|}{$5 \cdot 2$} & & \\
\hline Geriatric depression scale $(0-15)$ & & & & & $72 / 75$ & 0.695 \\
\hline Mean & \multicolumn{2}{|c|}{$4 \cdot 3$} & \multicolumn{2}{|c|}{4.1} & & \\
\hline SD & \multicolumn{2}{|c|}{$3 \cdot 1$} & \multicolumn{2}{|c|}{3.0} & & \\
\hline SMI (kg total muscle/m²) & & & & & $73 / 73$ & 0.983 \\
\hline Median & \multicolumn{2}{|c|}{8.5} & \multicolumn{2}{|c|}{8.4} & & \\
\hline Q1, Q3 & \multirow{2}{*}{\multicolumn{2}{|c|}{$7 \cdot 7,9 \cdot 6$}} & \multicolumn{2}{|c|}{$7 \cdot 5,10 \cdot 1$} & & \\
\hline CRP (mg/l) & & & & & $71 / 73$ & 0.864 \\
\hline Median & \multicolumn{2}{|c|}{29} & \multicolumn{2}{|c|}{29} & & \\
\hline Q1, Q3 & \multicolumn{2}{|c|}{7,62} & \multicolumn{2}{|c|}{2,77} & & \\
\hline Admission diagnosis & & & & & $73 / 75$ & 0.546 \\
\hline Fall & 9 & $12 \cdot 3$ & 13 & $17 \cdot 3$ & & \\
\hline Vertigo & 5 & $6 \cdot 8$ & 7 & $9 \cdot 3$ & & \\
\hline Infection & 17 & 23.3 & 22 & $29 \cdot 3$ & & \\
\hline Dehydration/electrolyte fluctuations & 4 & 5.5 & 3 & 4.0 & & \\
\hline Causa socialis & 7 & 9.6 & 10 & 13.3 & & \\
\hline Pain & 13 & $17 \cdot 8$ & 10 & $13 \cdot 3$ & & \\
\hline Other† & 18 & 24.7 & 10 & $13 \cdot 3$ & & \\
\hline Co-morbidities $\ddagger$ & & & & & $73 / 75$ & \\
\hline None & 20 & $27 \cdot 4$ & 24 & $32 \cdot 0$ & & 0.540 \\
\hline COPD & 13 & $17 \cdot 8$ & 7 & $9 \cdot 3$ & & 0.132 \\
\hline Cardiovascular & 34 & $46 \cdot 6$ & 39 & $52 \cdot 0$ & & 0.509 \\
\hline Diabetes mellitus & 9 & $12 \cdot 3$ & 12 & $16 \cdot 0$ & & 0.522 \\
\hline Other & 17 & 23.3 & 22 & $29 \cdot 3$ & & 0.404 \\
\hline Polyfarmaci ( $\geq 4$ medications) & 67 & $91 \cdot 8$ & 70 & $93 \cdot 3$ & $73 / 75$ & 0.719 \\
\hline Serum vitamin $\mathrm{D}_{3}(\mathrm{nmol} / \mathrm{l})$ & & & & & $65 / 66$ & 0.953 \\
\hline$\geq 100$ & 20 & $30 \cdot 8$ & 20 & $30 \cdot 3$ & & \\
\hline 50-99 & 34 & $52 \cdot 3$ & 36 & 54.5 & & \\
\hline$<50$ & 11 & $16 \cdot 9$ & 10 & $15 \cdot 2$ & & \\
\hline Nutritional risk (NRS-2002 $\geq 3$ ) & 15 & 20.5 & 25 & 33.8 & $73 / 74$ & 0.071 \\
\hline EWGSOP2 sarcopenia classification & & & & & $73 / 73$ & \\
\hline Sarcopenia & 20 & $27 \cdot 4$ & 20 & $27 \cdot 4$ & & 1.000 \\
\hline Severe sarcopenia & 18 & 24.7 & 17 & 23.3 & & 1.000 \\
\hline
\end{tabular}

SMI, skeletal muscle index; Q1, first quartile; Q3, third quartile; CRP, C-reactive protein; COPD, chronic obstructive pulmonary disease;

NRS-2002, Nutritional Risk Screening-2002; EWGSOP, European Working Group on Sarcopenia in Older People.

* Statistical tests: $\chi^{2} /$ Fisher's exact test (counts $\left.<5\right)(n$ and \%), Students' $t$ test (mean and sD) and Mann-Whitney U test (median and Q1, Q3).

† 'Other' mostly includes cardiovascular problems, dysregulated medication, dyspnoea, syncope.

‡ Patients can be reported under several categories, but only once under each. 'Other' mostly includes osteoporosis and arthritis.

$0 \cdot 44(\mathrm{IQR}-0 \cdot 08,0 \cdot 88) \mathrm{kg} / \mathrm{m}^{2} v$. placebo group: $1 \cdot 00$ (IQR 0.46, $\left.1.43) \mathrm{kg} / \mathrm{m}^{2}, P=0.032\right)$, which was also evident when looking at the entire intervention period (median, protein group: 0.19 (IQR $-0.57,1.04) \mathrm{kg} / \mathrm{m}^{2} v$. placebo group: 0.88 (IQR 0.33 , $\left.1.50) \mathrm{kg} / \mathrm{m}^{2}, P=0.050\right)$. Also, considering the entire intervention period, the placebo group exhibited a larger increase in 4-m gait speed (median, protein group: $0.03(\mathrm{IQR}-0.11,0.23) \mathrm{m} / \mathrm{s} v$. placebo group: $0.20(\mathrm{IQR} 0.08,0.33) \mathrm{m} / \mathrm{s}, P=0.026)$ and had a significantly higher increase in Barthel score (median, protein group: 13 (IQR 2, 21) $v$. placebo group: 21 (IQR 9, 39), $P=0.033$ ). Furthermore, the total LBM tended to increase more in the placebo group (median, protein group: $0 \cdot 40$ (IQR $-3 \cdot 20$, $1.90) \mathrm{kg} v$. placebo group: 1.70 (IQR -0.50, 5.40) kg, $P=0.052$ ).
Admission to hospital, length of stay and mortality during the study and follow-up. For the mITT analysis, the results for (re)admission to hospital, total length of stay(s) and mortality are shown in Table 7 , both during the 12 -week period after discharge and for the 6-month follow-up after the study intervention ended. There were no change between groups except for mortality in the follow-up period, where significantly more participants died in the protein group $(P=0.032)$. Reasons for dying are given in the table note and considered to be unrelated to the study interventions.

In the PP analysis, looking into the total length of stay as an average of all (re)admissions, during the entire intervention period, the protein group was admitted significantly longer than the placebo group (median, 11.5 (IQR 5, 17) $\mathrm{d} v .3$ (IQR 1, 3) d, 
Table 3. Resistance training (RT) and physical activity throughout the study period between groups* (Medians and interquartile ranges (Q1, Q3); mean values and $95 \%$ confidence intervals; numbers and percentages)

\begin{tabular}{|c|c|c|c|c|}
\hline & & & & oup \\
\hline & $n$ & $\%$ & $n$ & $\%$ \\
\hline RT, during the hospital admission $(n)$ & 73 & & 75 & \\
\hline RT (rounds/d, 0-9)† & & & & \\
\hline Mean & & & & \\
\hline $95 \% \mathrm{Cl}$ & & & & \\
\hline Days with RT of total LOS (\%) & & & & \\
\hline Median & & & & \\
\hline Q1, Q3 & & & & \\
\hline RT, 12 weeks after discharge $\ddagger(n)$ & $70 \S$ & & $71 \S$ & \\
\hline 1: No or very small amount of training & 17 & $24 \cdot 3$ & 18 & $25 \cdot 3$ \\
\hline 2: Small amount of training & 17 & $24 \cdot 3$ & 17 & 23.9 \\
\hline 3: Moderate amount of training & 6 & 8.6 & 8 & 11.3 \\
\hline 4: Regular amount of training & 18 & $25 \cdot 7$ & 20 & 28.2 \\
\hline 5: High amount of training & 12 & $17 \cdot 1$ & 8 & 11.3 \\
\hline Physical activity besides RT, 12 weeks after dischargeł $(n)$ & $70 \S$ & & $71 \S$ & \\
\hline 1: No or very little activity & 14 & $20 \cdot 0$ & 17 & 23.9 \\
\hline 2: Little activity & 30 & $42 \cdot 9$ & 31 & 43.7 \\
\hline 3: Moderate activity & 16 & 22.9 & 13 & $18 \cdot 3$ \\
\hline 4: Regular activity & 10 & $14 \cdot 3$ & 10 & 14.1 \\
\hline 5: High amount of activity & 0 & 0.0 & 0 & 0.0 \\
\hline
\end{tabular}

LOS, length of hospital stay; Q1, first quartile; Q3, third quartile.

* Statistical tests: Mann-Whitney Utest (median and Q1, Q3), Student's $t$ test (mean and $95 \% \mathrm{Cl}$ ) and $\chi^{2} /$ Fisher's exact test (counts $\left.<5\right)(n$ and \%). None of the tests was significant $(P>0.05)$.

$\dagger$ Based on daily records of the RT performed. Daily target was three exercises, three sets with ten repetitions. One round: $\geq 5$ repetitions of an exercise. Day of discharge not used to calculate the average.

$\ddagger$ Average estimates based on $4 \times$ activity interviews, covering the last week, every 3 weeks (average of three interviews $(n 9)$, one interview $(n 2)$ ). $\S$ Drop-outs not included.

Table 4. Average protein and energy intake during hospitalisation and after discharge, by treatment group (Medians and interquartile ranges (Q1, Q3))

\begin{tabular}{|c|c|c|c|c|c|c|c|c|}
\hline & \multicolumn{4}{|c|}{ During the hospital admissiont } & \multicolumn{4}{|c|}{ During the 12 weeks after discharge } \\
\hline & \multicolumn{2}{|c|}{ Protein } & \multicolumn{2}{|c|}{ Placebo } & \multicolumn{2}{|c|}{ Protein } & \multicolumn{2}{|c|}{ Placebo } \\
\hline & Median & Q1, Q3 & Median & Q1, Q3 & Median & Q1, Q3 & Median & Q1, Q3 \\
\hline From the diet $\neq(n)$ & \multicolumn{2}{|c|}{70} & \multicolumn{2}{|c|}{74} & \multicolumn{2}{|c|}{70} & \multicolumn{2}{|c|}{71} \\
\hline Protein $(\mathrm{g} / \mathrm{d})$ & 42 & 36,52 & 42 & 30,52 & 54 & 43,64 & 56 & 44,68 \\
\hline Protein $(\mathrm{g} / \mathrm{kg} \S$ per $\mathrm{d})$ & 0.6 & $0.5,0.8$ & 0.6 & $0.5,0.8$ & 0.8 & $0.7,1 \cdot 0$ & 0.8 & $0 \cdot 6,1 \cdot 0$ \\
\hline Energy $(\mathrm{MJ} / \mathrm{d})$ & $5 \cdot 3$ & $4 \cdot 4,6 \cdot 2$ & $5 \cdot 1$ & $3 \cdot 7,6 \cdot 0$ & $5 \cdot 4$ & $4 \cdot 8,6 \cdot 8$ & $5 \cdot 8$ & $4 \cdot 9,7 \cdot 2$ \\
\hline From PrSII $(n)$ & \multicolumn{2}{|c|}{73} & \multicolumn{2}{|c|}{75} & \multicolumn{2}{|c|}{70} & \multicolumn{2}{|c|}{71} \\
\hline Protein $(\mathrm{g} / \mathrm{d})$ & 26 & 22,28 & $1.4^{*}$ & $1.3,1.5$ & 19 & 10,24 & $1.0^{*}$ & $0 \cdot 1,1 \cdot 4$ \\
\hline Protein $(\mathrm{g} / \mathrm{kg} \S$ per d) & 0.4 & $0.3,0.4$ & $0.0^{*}$ & $0.0,0.0$ & 0.3 & $0.1,0.4$ & $0.0^{*}$ & $0.0,0.0$ \\
\hline Energy $(\mathrm{MJ} / \mathrm{d})$ & 2.0 & $1 \cdot 7,2 \cdot 1$ & $2 \cdot 0^{\star \star}$ & $1 \cdot 8,2 \cdot 1$ & 1.4 & $0.8,1.9$ & 1.4 & $0.1,1.9$ \\
\hline Total intake $(n)$ & \multicolumn{2}{|c|}{70} & \multicolumn{2}{|c|}{74} & \multicolumn{2}{|c|}{70} & \multicolumn{2}{|c|}{71} \\
\hline Protein $(\mathrm{g} / \mathrm{d})$ & 68 & 56,79 & $43^{*}$ & 31,54 & 72 & 57,81 & $56^{*}$ & 44,69 \\
\hline Protein $(\mathrm{g} / \mathrm{kg} \S$ per $\mathrm{d})$ & 1.0 & $0.8,1.3$ & $0.6^{*}$ & $0.5,0.8$ & 1.1 & $0.9,1.3$ & $0.9^{*}$ & $0.6,1.0$ \\
\hline Energy $(\mathrm{MJ} / \mathrm{d})$ & $7 \cdot 3$ & $6 \cdot 1,8 \cdot 3$ & 6.9 & $5 \cdot 4,7 \cdot 9$ & 6.9 & $6 \cdot 1,7 \cdot 8$ & 7.5 & $5 \cdot 6,8 \cdot 9$ \\
\hline
\end{tabular}

Q1, first quartile; Q3, third quartile; PrS, protein supplementation.

${ }^{*} P<0.0001,{ }^{* *} P<0.05$ (Mann-Whitney $U$ test).

$\dagger$ Drop-outs not included.

$\ddagger$ Hospital: estimated by daily records for up to $4 \mathrm{~d}$ ( $n$ 87) (average of $3 \mathrm{~d}(n 27)$, average of $2 \mathrm{~d}(n 22), 1 \mathrm{~d}(n 8)$, due to early discharge, missing ( $n 4)$ ). After discharge, average intake estimated by means of $4 \times$ dietary interviews $(n 131)$ every 3 weeks (average of three interviews $(n 9)$, one interview $(n 1)$ ).

$\S$ Hospital: calculated with baseline body weight as a reference. For 12 weeks after discharge: calculated with an average of post-discharge and final body weight as a reference. If values are missing, then it is calculated from the remaining measure.

II Hospital: calculated from daily records. For 12 weeks after discharge: calculated based on the collection of empty bottles and participants' study product diaries (average of total intake divided by the respective study periods).

$P=0 \cdot 014)$. However, looking at the 6-month follow-up period, the picture changed, and the participants in the protein group were admitted for a significantly shorter period (median, 4.5 (IQR 3, 6.5) v. 9 (IQR 7, 14) d, $P=0.032$ ). No differences were found with respect to (re)admission or mortality.
Residence, home care and use of gait aids. These variables were only compared for changes occurring throughout the entire intervention period, as these changes take some time to manifest. Most participants in both groups were admitted from own house/apartment (protein group: $91.4 \% v$. placebo group: 
Table 5. Results for the primary endpoint, changes in performance between groups, modified intention-to-treat analysis* (Medians and interquartile ranges (Q1, Q3); numbers and percentages)

\begin{tabular}{|c|c|c|c|c|c|c|c|c|c|c|c|c|}
\hline & \multicolumn{4}{|c|}{ Protein group } & \multicolumn{4}{|c|}{ Placebo group } & \multirow[b]{2}{*}{$P \S$} & \multirow[b]{2}{*}{$P \|$} & \multirow[b]{2}{*}{$P \emptyset$} & \multirow[b]{2}{*}{$P^{\star *}$} \\
\hline & $\begin{array}{l}\text { Baseline } \\
\text { test }\end{array}$ & $\begin{array}{c}\Delta \dagger \\
\text { Baseline } \\
\text { to } \\
\text { discharge } \neq\end{array}$ & $\begin{array}{c}\Delta \\
\text { Discharge } \\
\text { to } 12 \\
\text { weeks } \\
\text { after }\end{array}$ & $\begin{array}{c}\Delta \\
\text { Baseline } \\
\text { to } 12 \\
\text { weeks } \\
\text { after } \\
\text { discharge }\end{array}$ & $\begin{array}{c}\text { Baseline } \\
\text { test }\end{array}$ & $\begin{array}{c}\Delta \text { Baseline } \\
\text { to } \\
\text { discharge } \neq\end{array}$ & $\begin{array}{c}\Delta \\
\text { Discharge } \\
\text { to } 12 \\
\text { weeks } \\
\text { after }\end{array}$ & $\begin{array}{c}\Delta \\
\text { Baseline } \\
\text { to } 12 \\
\text { weeks } \\
\text { after } \\
\text { discharge }\end{array}$ & & & & \\
\hline $\begin{array}{l}\text { 30-s CST std. (no. of } \\
\text { stands } \dagger \text { ) }\end{array}$ & & & & & & & & & 0.707 & 0.954 & 0.164 & 0.226 \\
\hline Median & 0 & 0 & 0 & 0 & 0 & 0 & 1 & 2 & & & & \\
\hline Q1, Q3 & 0,8 & 0,1 & 0,3 & 0,5 & 0,6 & 0,2 & 0,6 & 0,6 & & & & \\
\hline$n$, analysis & 73 & 71 & 66 & 67 & 75 & 75 & 71 & 71 & & & & \\
\hline $\begin{array}{l}\text { 30-s CST mod. (no. of } \\
\text { stands†t) }\end{array}$ & & & & & & & & & 0.701 & 0.322 & 0.892 & 0.697 \\
\hline Median & 6 & 1 & 0 & 2 & 5 & 1 & 1 & 2 & & & & \\
\hline Q1, Q3 & 3,8 & 0,3 & $-1,3$ & 0,5 & 3,7 & $-1,3$ & 0,3 & $-1,5$ & & & & \\
\hline$n$, analysis & 44 & 37 & 33 & 35 & 45 & 41 & 34 & 33 & & & & \\
\hline \multicolumn{13}{|l|}{ 30-s CST progression } \\
\hline Improvement & - & & & & - & & & & - & 0.348 & 0.042 & 0.664 \\
\hline$n$ & & 47 & 40 & 48 & & 44 & 53 & 51 & & & & \\
\hline$\%$ & & $66 \cdot 2$ & $60 \cdot 6$ & $70 \cdot 6$ & & $58 \cdot 7$ & $76 \cdot 8$ & 73.9 & & & & \\
\hline No change & - & & & & - & & & & - & 0.895 & 0.023 & 0.056 \\
\hline$n$ & & 10 & 9 & 12 & & 10 & 2 & 5 & & & & \\
\hline$\%$ & & $14 \cdot 1$ & $13 \cdot 6$ & $17 \cdot 6$ & & $13 \cdot 3$ & $2 \cdot 7$ & $7 \cdot 2$ & & & & \\
\hline Decline & - & & & & - & & & & - & $0 \cdot 241$ & 0.450 & 0.250 \\
\hline$n$ & & 14 & 17 & 8 & & 21 & 14 & 13 & & & & \\
\hline$\%$ & & $19 \cdot 7$ & $25 \cdot 8$ & $11 \cdot 8$ & & $28 \cdot 0$ & $18 \cdot 7$ & $18 \cdot 8$ & & & & \\
\hline$n$, analysis & & 71 & 66 & 68 & & 75 & 69 & 69 & & & & \\
\hline Stand, no use of arms & & & & & & & & & 0.973 & 0.143 & 0.073 & 0.480 \\
\hline$n$ & 29 & 2 & 8 & 11 & 30 & -1 & 17 & 15 & & & & \\
\hline$\%$ & 39.7 & $2 \cdot 8$ & $12 \cdot 1$ & $16 \cdot 4$ & $40 \cdot 0$ & $-1 \cdot 3$ & 23.9 & $21 \cdot 1$ & & & & \\
\hline$n$, analysis & 73 & 71 & 66 & 67 & 75 & 75 & 71 & 71 & & & & \\
\hline
\end{tabular}

CST, chair stand test; std, standard (arms crossed across the chest); Q1, first quartile; Q3, third quartile; mod, modified (use of help, e.g. arm rest).

* Statistical tests: Mann-Whitney $U$ test (median and Q1, Q3) and $\chi^{2} /$ Fisher's exact test (counts $\left.<5\right)(n$ and \%).

$\dagger \Delta$ : indicates changes.

† Duration in days (median and Q1, Q3): protein group $(5$ and 4,8$) \mathrm{d}$ and placebo group $(5$ and 3,8$) \mathrm{d}$.

$\S P$ values for differences between groups at baseline (upon admission to hospital).

II $P$ values for differences in changes in performance between groups during the period of hospitalisation.

I $P$ values for differences in changes in performance between groups during the 12 -week period after discharge.

${ }_{\star \star} P$ values for differences in changes in performance between groups for the entire study intervention period.

$\dagger+$ No differences between groups in height of chair at any time point (average height $=44.81 \mathrm{~cm}$ ).

$97.2 \%)$. At the end of their intervention period, a couple of participants in both groups had moved to a nursing home/sheltered housing (protein group: $4.3 \% v$. placebo group: $2.8 \%$, $P=0.681$ ). The number of participants receiving help/any kind of home care increased during the intervention period in both groups (protein group: 61.4 to $71.4 \%(P=0.210)$ and placebo group: 63.4 to $74.6 \%(P=0 \cdot 147))$ but were not different between groups $(P=0.807)$. Despite an increasing need for help, a decrease in the number of participants who needed gait aids during the intervention period was found in both groups, without differing between groups (protein group: 71.4 to $60.0 \%$ and placebo group: 80.3 to $63.4 \%, P=0.352$ ). The primary gait aid used in both groups was a walker, followed by a walking stick. The PP analysis overall had the same findings (results not shown).

\section{ANCOVA for primary and secondary endpoints}

The test prerequisites were met only for the endpoints: 30-s CSTmodified, handgrip strength, MMSE and quality of life-VAS (mITT analysis). A significant difference was seen only for handgrip strength, during the 12-week period after discharge, in favour of the placebo group (median, protein group: $0 \cdot 25$ (IQR -0.61, 1.11 ) and placebo group: 1.55 (IQR 0.68, 2.42), $P=0.039$ ), and this finding was the same as in the unadjusted mITT analysis.

\section{Subgroup analysis}

The number of participants at nutritional risk (NRS-2002 ${ }^{(30)}$ ) at baseline was 15 and 25 in the protein group and placebo group, respectively. The sub-group analysis, including only these participants, did not result in any significant differences.

Both in the protein and placebo group, twenty participants were classified as sarcopenic at baseline, Of these, eighteen and seventeen participants were considered severely sarcopenic in the protein and placebo group, respectively (EWGSOP2 definition $^{(1)}$. Also, subgroup analysis including these participants did not result in any significant differences between groups.

\section{Discussion}

The present study did not find additive effects on any endpoints of PrS in acutely ill hospitalised older adults offered standardised 


\section{N British Journal of Nutrition}

Table 6. Results for the secondary endpoints, changes in performance between groups, modified intention-to-treat analysis ${ }^{\star}$ (Medians and interquartile ranges (Q1, Q3))

\begin{tabular}{|c|c|c|c|c|c|c|c|c|c|c|c|c|}
\hline & \multicolumn{4}{|c|}{ Protein group } & \multicolumn{4}{|c|}{ Placebo group } & \multirow[b]{2}{*}{$P \S$} & \multirow[b]{2}{*}{$P \|$} & \multirow[b]{2}{*}{$P q$} & \multirow[b]{2}{*}{$P^{\star *}$} \\
\hline & $\begin{array}{c}\text { Baseline } \\
\text { test }\end{array}$ & $\begin{array}{c}\Delta \dagger \text { Baseline } \\
\text { to discharge }\end{array}$ & $\begin{array}{c}\Delta \text { Discharge } \\
\text { to } 12 \text { weeks } \\
\text { after }\end{array}$ & $\begin{array}{c}\Delta \text { Baseline to } 12 \\
\text { weeks after } \\
\text { discharge }\end{array}$ & $\begin{array}{c}\text { Baseline } \\
\text { test }\end{array}$ & $\begin{array}{c}\Delta \text { Baseline to } \\
\text { discharge } \neq\end{array}$ & $\begin{array}{c}\Delta \text { Discharge } \\
\text { to } 12 \text { weeks } \\
\text { after }\end{array}$ & $\begin{array}{c}\Delta \text { Baseline to } 12 \\
\text { weeks after } \\
\text { discharge }\end{array}$ & & & & \\
\hline \multicolumn{13}{|l|}{ Body composition†† } \\
\hline Total LBM (kg) & & & & & & & & & 0.721 & 0.332 & 0.803 & 0.716 \\
\hline Median & $44 \cdot 0$ & -0.3 & 0.9 & 0.8 & 42.5 & -0.1 & 0.8 & 0.9 & & & & \\
\hline Q1, Q3 & $36 \cdot 6,49 \cdot 9$ & $-2 \cdot 1,0 \cdot 8$ & $-0 \cdot 2,3 \cdot 2$ & $-1.5,3.3$ & $38 \cdot 6,52 \cdot 2$ & $-1 \cdot 3,0 \cdot 8$ & $-0.7,2.6$ & $-0 \cdot 6,2 \cdot 8$ & & & & \\
\hline LBM arms (kg) & & & & & & & & & 0.932 & 0.117 & 0.415 & 0.790 \\
\hline Median & 4.7 & -0.1 & 0.0 & 0.0 & 4.3 & -0.05 & 0.0 & -0.1 & & & & \\
\hline Q1, Q3 & $3 \cdot 4,5 \cdot 4$ & $-0.4,0.0$ & $-0.2,0.4$ & $-0.5,0.3$ & $3 \cdot 6,5 \cdot 8$ & $-0 \cdot 2,0.1$ & $-0 \cdot 2,0 \cdot 3$ & $-0.4,0.2$ & & & & \\
\hline LBM legs (kg) & & & & & & & & & 0.489 & 0.979 & 0.206 & 0.319 \\
\hline Median & $12 \cdot 2$ & 0.2 & 0.5 & 0.8 & 11.8 & 0.1 & 0.7 & 1.0 & & & & \\
\hline Q1, Q3 & $9 \cdot 0,14 \cdot 3$ & $-0 \cdot 3,0.7$ & $-0 \cdot 2,1 \cdot 1$ & $0.0,1.5$ & $9 \cdot 9,15 \cdot 3$ & $-0 \cdot 2,0.7$ & $0 \cdot 1,1 \cdot 4$ & $0.3,1.5$ & & & & \\
\hline LBM torso $(\mathrm{kg})$ & & & & & & & & & 0.913 & 0.246 & 0.622 & 0.960 \\
\hline Median & $19 \cdot 1$ & -0.2 & 0.2 & 0.05 & 19.6 & -0.2 & 0.1 & -0.2 & & & & \\
\hline Q1, Q3 & $16 \cdot 1,22 \cdot 3$ & $-0.9,-0.2$ & $-0.4,1.0$ & $-1 \cdot 1,0 \cdot 7$ & $16 \cdot 5,22 \cdot 6$ & $-0.6,0.3$ & $-0.5,0.8$ & $-0.9,0.7$ & & & & \\
\hline Total FM (kg) & & & & & & & & & 0.450 & 0.437 & 0.454 & 0.730 \\
\hline Median & $21 \cdot 6$ & 0.1 & -0.3 & 0.2 & 24.9 & 0.1 & -0.05 & -0.4 & & & & \\
\hline Q1, Q3 & $16 \cdot 5,28 \cdot 4$ & $-0 \cdot 7,1 \cdot 2$ & $--2 \cdot 2,1 \cdot 4$ & $-2 \cdot 0,1 \cdot 5$ & $16 \cdot 3,31 \cdot 5$ & $-0 \cdot 8,1 \cdot 0$ & $-2 \cdot 3,2 \cdot 3$ & $-2 \cdot 5,1 \cdot 6$ & & & & \\
\hline$n$, analysis & 72 & 69 & 64 & 66 & 72 & 66 & 60 & 61 & & & & \\
\hline BMI $\left(\mathrm{kg} / \mathrm{m}^{2}\right)$ & & & & & & & & & 0.508 & 0.554 & 0.528 & 0.600 \\
\hline Median & $25 \cdot 3$ & -0.08 & 0.4 & 0.2 & $25 \cdot 1$ & 0.04 & 0.5 & 0.5 & & & & \\
\hline Q1, Q3 & $22 \cdot 3-27 \cdot 0$ & $-0.4,0.3$ & $-0.2,0.9$ & $-0.5,1.0$ & $21 \cdot 7,30 \cdot 0$ & $-0.4,0.3$ & $-0 \cdot 3-1 \cdot 2$ & $-0.5,1.0$ & & & & \\
\hline$n$, analysis & 73 & 70 & 66 & 69 & 75 & 74 & 65 & 66 & & & & \\
\hline Handgrip strength $(\mathrm{kg})$ & & & & & & & & & 0.977 & 0.681 & 0.026 & 0.115 \\
\hline Median & $17 \cdot 8$ & 0.2 & 0.1 & 0.44 & $17 \cdot 7$ & -0.3 & 1.4 & 0.7 & & & & \\
\hline Q1, Q3 & $13 \cdot 3,23 \cdot 3$ & $-1 \cdot 9,1 \cdot 6$ & $-2 \cdot 3,2 \cdot 4$ & $-2 \cdot 8,1 \cdot 8$ & $13 \cdot 1,22 \cdot 7$ & $-2 \cdot 2,2 \cdot 3$ & $-0.7,3.5$ & $-1 \cdot 8,4 \cdot 0$ & & & & \\
\hline$n$, analysis & 73 & 72 & 69 & 70 & 75 & 75 & 68 & 68 & & & & \\
\hline DEMMI (0-100) & & & & & & & & & 0.763 & 0.994 & 0.525 & 0.510 \\
\hline Median & 53 & 4 & 3.5 & 9 & 53 & 5 & 5 & 10 & & & & \\
\hline Q1, Q3 & 44,67 & 0,12 & $-4,14$ & 0,20 & 44,62 & $-3,9$ & $-1,18$ & 0,22 & & & & \\
\hline$n$, analysis & 73 & 71 & 68 & 69 & 75 & 75 & 70 & 70 & & & & \\
\hline 4-m gait speed $(\mathrm{m} / \mathrm{s})$ & & & & & & & & & 0.055 & 0.481 & 0.193 & 0.069 \\
\hline Median & 0.6 & 0.0 & 0.1 & 0.05 & 0.5 & 0.0 & 0.1 & 0.2 & & & & \\
\hline Q1, Q3 & $0.5,0.9$ & $-0.1,0.1$ & $-0.1,0.2$ & $-0.1,0.2$ & $0.4,0.7$ & $-0 \cdot 1,0.2$ & $-0.05,0.3$ & $-0.1,0.4$ & & & & \\
\hline$n$, analysis & 73 & 71 & 65 & 67 & 75 & 72 & 65 & 66 & & & & \\
\hline Barthel (0-100) & & & & & & & & & 0.119 & 0.052 & 0.985 & 0.097 \\
\hline Median & 79 & 10 & 0 & 15 & 76 & 19 & 0 & 20 & & & & \\
\hline Q1, Q3 & 68,93 & 2,24 & $-2,8$ & 5,24 & 58,87 & 4,30 & $-1,7$ & 6,32 & & & & \\
\hline$n$, analysis & 68 & 67 & 69 & 65 & 71 & 71 & 71 & 67 & & & & \\
\hline MMSE score $(0-30)$ & & & & & & & & & 0.666 & 0.958 & 0.152 & 0.457 \\
\hline Median & 26 & 1 & 0 & 1 & 26 & 0 & -1 & 0 & & & & \\
\hline Q1, Q3 & 24,28 & $-1,2$ & $-1,2$ & 0,2 & 23,28 & $-1,3$ & $-1,1$ & $-1,3$ & & & & \\
\hline$n$, analysis & 73 & 72 & 69 & 69 & 75 & 75 & 70 & 70 & & & & \\
\hline
\end{tabular}


RT during admission and 12 weeks after discharge. However, both groups improved significantly for most parameters, and specifically the increase in LBM shows an adaptive response to the RT in agreement with the previous studies ${ }^{(11,14-19,22-24)}$ and established knowledge ${ }^{(45)}$. The placebo group generally improved more than the protein group, which is unexpected, as most systematic reviews and meta-analysis find additional effects of $\operatorname{PrS}^{(11,14,17-19,23)}$, with only a few finding no effects ${ }^{(15,24)}$ or conflicting results ${ }^{(16,21,22)}$. However, regarding previous studies, it is hard to compare them directly as the study designs are very heterogenous. Also, only a minority report the total protein intake or activity besides the RT, which are known confounders. Furthermore, no one has to our knowledge included very old geriatric medical patients. The two sub-group analyses comparing only those at nutritional risk and those who were sarcopenic at baseline also did not find any significant differences between groups, despite the hypothesis of a higher benefit from PrS. However, the statistical power was low, and generally the effect of RT and/or general recovery from illness may have dominated. Post hoc, observational analysis revealed that total physical activity (RT + habitual activity) was significantly correlated to improvements in most end points (ANCOVA, results not shown). Regarding mortality, significantly more patients in the protein group died during the 6-month follow-up period (Table 7), but this is considered a spurious finding unrelated to study participation. Most died while admitted to hospital with pneumonia or urinary infection, which are on the top three of the most encountered diagnoses in Danish geriatric medical patients ${ }^{(46)}$. Furthermore, the mortality rate was much lower than expected for the present study population ${ }^{(47,48)}$, and potential confounding factors were not monitored in the follow-up period.

During hospitalisation, the protein group received on average $1.0 \mathrm{~g}$ protein $/ \mathrm{kg}$ per $\mathrm{d}$ from the diet and $\mathrm{PrS}$, and the placebo group received $0.6 \mathrm{~g}$ protein $/ \mathrm{kg}$ per $\mathrm{d}$, which for both groups is lower than the recommendation for acutely ill older adults of $1.2-1.5 \mathrm{~g} / \mathrm{kg}$ per $\mathrm{d}^{(49)}$. After discharge the intake increased to $1.1 \mathrm{~g}$ protein $/ \mathrm{kg}$ per $\mathrm{d}$ in the protein group, being within the recommended range of intake for healthy older adults (without malnutrition) of at least $1 \cdot 0-1 \cdot 3 \mathrm{~g} / \mathrm{kg}$ per $\mathrm{d}^{(49,50)}$. These said, generally dietary requirements are probably higher for geriatric patients than for healthy older adults in the period right after discharge, as lose in LBM needs to be recovered ${ }^{(50)}$ and stress metabolism may persist for a little while. Also, $27 \%$ of participants were screened to be at risk of malnutrition at admission, likewise increasing requirements to enable gain in LBM. In comparison, the placebo group received $0.9 \mathrm{~g}$ protein $/ \mathrm{kg}$ per $\mathrm{d}$ after discharge, which was significantly lower compared with the protein group and below protein recommendations. However, despite being statistically significant, the difference in protein intake between the groups was small $(0.2 \mathrm{~g} / \mathrm{kg}$ per d) due to the low compliance with study supplements. A large meta-analysis, including adults performing regularly RT, showed a linear dose-response relationship between the total daily protein intake and increases in LBM, until a break point of $1.6 \mathrm{~g} / \mathrm{kg}$ per $\mathrm{d}^{(17)}$ was achieved. Acute feeding/metabolic studies in older adults have also shown a saturable linear dose-response relationship between per-meal protein intake and post-prandial muscle protein synthesis (MPS) ${ }^{(51-53)}$, with a threshold of $0 \cdot 40\left(\right.$ SD 0 19) $\mathrm{g} / \mathrm{kg}$ per meal ${ }^{(52)}$. 
Table 7. Admission to hospital, length of stay and mortality between groups* (Medians and interquartile ranges (Q1, Q3); numbers and percentages)

\begin{tabular}{|c|c|c|c|c|c|}
\hline & \multicolumn{2}{|c|}{ Protein group } & \multicolumn{2}{|c|}{ Placebo group } & \multirow[b]{2}{*}{$P$} \\
\hline & $n$ & $\%$ & $n$ & $\%$ & \\
\hline During the 12 weeks after discharge $(n)$ & 73 & & 75 & & \\
\hline Mortality $\dagger$ & 0 & 0 & 0 & 0 & 1.000 \\
\hline Admission to hospital & & & & & 0.287 \\
\hline No. of admissions & 53 & 72.6 & 60 & $80 \cdot 0$ & \\
\hline One admission & 16 & 21.9 & 12 & $16 \cdot 0$ & \\
\hline Two admissions & 2 & $2 \cdot 7$ & 3 & 4.0 & \\
\hline Three admissions & 2 & $2 \cdot 7$ & 0 & 0.0 & \\
\hline Total LOS (d)‡ & & & & & 0.591 \\
\hline Median & \multicolumn{2}{|c|}{6.5} & \multicolumn{2}{|c|}{6} & \\
\hline Q1, Q3 & \multicolumn{2}{|c|}{5,16} & \multicolumn{2}{|c|}{3,17} & \\
\hline Days before one admission & & & & & 0.934 \\
\hline Median & \multicolumn{2}{|c|}{23} & \multicolumn{2}{|c|}{27} & \\
\hline Q1, Q3 & \multicolumn{2}{|c|}{4,49} & \multicolumn{2}{|c|}{13,35} & \\
\hline 6 months after study intervention $(n)$ & 73 & & 75 & & \\
\hline Mortality $\dagger$ & 7 & $9 \cdot 6$ & 1 & 1.3 & 0.032 \\
\hline Admission to hospital & & & & & 0.634 \\
\hline No. of admissions & 47 & $71 \cdot 2$ & 53 & 71.6 & \\
\hline One admission & 17 & $25 \cdot 8$ & 17 & 23.0 & \\
\hline Two admissions & 1 & 1.5 & 3 & $4 \cdot 1$ & \\
\hline Three admissions & 1 & 1.5 & 1 & 1.4 & \\
\hline Total LOS (d)‡ & \multirow{2}{*}{\multicolumn{2}{|c|}{5}} & & & 0.154 \\
\hline Median & & & \multicolumn{2}{|c|}{9} & \\
\hline Q1, Q3 & \multicolumn{2}{|c|}{3,12} & \multicolumn{2}{|c|}{5,14} & \\
\hline
\end{tabular}

Based on the latter finding, it is hypothesised that the daily distribution of the total protein intake might have an independent anabolic influence, even though the most optimal distribution pattern is debated. One theory is that a balanced protein distribution, where the protein intake in main meals reaches the threshold for maximal MPS, is the most optimal ${ }^{(54-56)}$. However, arguments also exist that a protein intake beyond this plateau continues to be beneficial, as the net anabolic effect increases due to the suppression of muscle protein breakdown ${ }^{(54)}$. Nevertheless, considering the total daily protein intake in the protein group of about $67 \mathrm{~g}$, this is far below the $1.6 \mathrm{~g} / \mathrm{kg}$ per $\mathrm{d}$ threshold, which also makes it less likely that they reached the maximal threshold for the meals (equal to $26 \cdot 6$ (sD 5.6) g protein, based on baseline body weight). Consequently, due to the linear dose-response relationship of MPS until reaching the thresholds for both per-meal and total daily protein intake, any increase in protein intake should, theoretically, be beneficial. This expectation is strengthened by the fact that RT sensitises muscles to amino acids ${ }^{(57)}$. However, the present study illustrates that a difference in total protein intake of $0.4 \mathrm{~g} / \mathrm{kg}$ per d during hospitalisation and $0.2 \mathrm{~g} / \mathrm{kg}$ per $\mathrm{d}$ after discharge, when simultaneously following a low-intensity/volume RT program, is not enough to elicit a measurable and clinically meaningful change in outcome variables between groups. Looking only at the participants having high compliance with supplements, the difference in total protein intake was $0.4 \mathrm{~g} / \mathrm{kg}$ per d during hospitalisation and $0.3 \mathrm{~g} / \mathrm{kg}$ per $\mathrm{d}$ after discharge. However, the PP analysis did not change the conclusions considerably, but the statistical power was also lower. A study with older hospitalised adults given $\operatorname{PrS}(24 \mathrm{~g} / \mathrm{d})$ and RT or RT only showed positive effects of PrS during the length of hospital admission which was $>20 \mathrm{~d}$ for both groups ${ }^{(58)}$. Thus, the short length of hospital stay for all participants in the present study (median of $5 \mathrm{~d}$ ) may have blunted the chance of finding positive effects of the greater difference in protein intake between groups looking only at the hospitalisation period. In relation to protein distribution/timing theories, the consumption of smaller amounts of protein throughout the whole day in the present study population might also have influenced the outcomes.

Previously, it has been found that the sensitivity of muscle to PrS increases with the duration, frequency and volume of $\mathrm{RT}^{(59)}$. In that perspective, our 12-week intervention period might have been too short to allow for a significant additional effect of PrS, or our home-based RT programme might have been performed with too low intensity or the RT compliance was too low (Table 3). Furthermore, research indicate that resistance-trained individuals benefit more from PrS during RT compared with the untrained individuals ${ }^{(17,59,60)}$, and the participants in the present study were not pre-conditioned to RT. Also, the fact that the placebo group received isoenergetic supplements may have blunted the chance of finding significant effects of PrS, as sufficient energy intake can preserve LBM and is a prerequisite for ingested protein to be available for MPS ${ }^{(61,62)}$. The energy intake, $\mathrm{RT}$ and outcomes were increased or improved in both groups by 
the intervention, and perhaps the independent effect of energy supplementation/meeting energy requirements in the context of RT deserves more attention in future studies. For example, in the opposite scenario, one could fear that an energy deficit during RT would impair convalescence after RT and, in the worst case, be detrimental. Confounding factors, known and unknown, explaining the unexpected, more favourable effects in the placebo group, cannot be ruled out. Especially, differences in recovery from the acute illness and/or co-morbidities may have greatly influenced study conclusions. Block randomisation according to recruitment site was chosen to eliminate potential bias related to, for example, specific hospital care and residence/ municipality. No statistically significant differences were seen for any of the measured confounders. However, the median total energy intake in the placebo group was a little higher during the 12 weeks after discharge, which was related to a nonsignificantly higher dietary energy intake (Table 4). This higher dietary intake may be associated with the lower satiety rating of the supplements in the placebo group. Likewise, the RT amount during admission was a little higher in the placebo group, though not statistically significant (Table 3). Also, baseline characteristics were not statistically different between groups. However, in an observational analysis, exploring the factors that had influence on changes from baseline, besides the amount of total activity (RT + habitual activity), a low baseline value was found to be significantly associated with higher improvements for most endpoints, and the placebo group was at a lower baseline level than the protein group for the endpoints shown to be significant in either the mITT or PP analyses. Thus, overall randomisation might not have been successful, and results may have been biased. Not the least, because of test multiplicity, caution must be shown not to overinterpret these findings.

The present study has limitations, some of which are discussed in the published study protocol, for example, the use of BIA to measure $\mathrm{LBM}^{(27)}$. Also, supervised RT lead to higher RT compliance in previous studies ${ }^{(16)}$. However, many geriatric patients find it very burdensome to leave their homes, and, therefore, self-training at home was chosen. The use of 24-h recall interviews in estimating dietary protein and energy intake was chosen to minimise the study burden but is criticised for underestimating intake - especially carbohydrate-rich foods ${ }^{(63)}$. However, calculating the participants' basal metabolic rate (original Harris-Benedict equation) and estimating the activity factor (protein group: 1.37 (SD 0.26) and placebo group: 1.31 (sD 0.36)), while taking into account the increase in body weight and self-reported RT and activity level (Table 3), the reporting seems very reasonable. The greatest limitation is considered to be the low compliance to the supplements, which diminishes the strength of the low rate of exclusions/dropouts and high study power. It was the general experience that poor health, including disease- and age-related anorexia, was the major reason. Therefore, a higher dose of PrS would probably not have increased the actual protein intake from the supplements and subsequently resulted in a greater difference in protein intake between groups. The compliance might have been higher if the PrS had come in different flavours, as some participants also reported taste fatigue. However, to significantly increase compliance/total protein intake in a population of geriatric medical patients, many of whom have low appetite and are malnourished $^{(25,64)}$, a more holistic approach might be necessary. Thus, future studies, focusing on PrS in addition to proteinrich/enriched foods of high protein quality, maybe combined with dietary counselling would seem to be relevant in this population. Also, one could consider leucine supplementation, which has shown promising results in other studies with healthy older adults $^{(13,65,66)}$, and can be given in smaller volumes or capsules, compromising appetite to a less degree. Furthermore, future studies could tackle the heterogeneity of geriatric medical patients by stratifying according to, for example, the number of co-morbidities or another measure for severity of illness, or chose to only include certain sub-groups.

\section{Conclusion}

In the present study, no additive effect of PrS during and 12 weeks after hospital admission was found in geriatric medical patients offered low-intensity RT and isoenergetic placebo supplements. This might be explained by a low difference in total protein intake between groups of $0.4 \mathrm{~g} / \mathrm{kg}$ per d during hospitalisation and $0.2 \mathrm{~g} / \mathrm{kg}$ per $\mathrm{d}$ after discharge. However, based on LBM gain observed in both groups, the study supports the established knowledge of RT as a potent strategy to counteract sarcopenia. More studies are necessary to establish the importance of different aspects of the study design, and identification of better ways to increase the compliance and total protein intake in geriatric medical patients would be highly relevant.

\section{Acknowledgements}

We want to thank all the participants and their relatives and the research assistants and physiotherapists working on the study. Also, we want to thank the three recruitment sites, the sponsors and everyone who helped with the study along the way.

The Research Unit of Clinical Nutrition at Herlev and Gentofte Hospital is the initiator of this research study. The Danish Dairy Research Foundation, section of 'Health and Nutrition', is the head sponsor. They had no role in the design, analysis or writing of this article. Other funding comes from Copenhagen University, faculty of Nutrition, Exercise and Sports, and The Nutrition Unit at Herlev and Gentofte Hospital. Furthermore, Arla Foods Amba and Arla Foods Ingredients have funded the study, including the delivery of the intervention products. Thus, the design has indirectly been influenced by the kind of intervention products (e.g. flavour, placebo products) they could apply. Otherwise, they had no role in the design, analysis and interpretation of data.

A. M. B., J. G., A. V., B. C., and A. A. designed the research; JG was responsible for trial execution and data collection under supervision of A. M. B., A. V., B. C. and A. A.; F. R. and H. E. A. provided access to potential study participants and facilitated study recruitment; J. G. analysed data supported by T. W. C.; J. G. wrote the first draft of the manuscript, which was critically reviewed and improved by all authors. J. G. had the primary responsibility for the final content. All authors read and approved the final manuscript. 
None of the authors declares any conflicts of interests, financial or otherwise. B. C. is employed at Arla Foods Amba.

\section{Supplementary material}

For supplementary material/s referred to in this article, please visit https://doi.org/10.1017/S0007114519001831

\section{References}

1. Cruz-Jentoft AJ, Bahat G, Bauer J, et al. (2018) Sarcopenia: revised European consensus on definition and diagnosis. Age Ageing 48, 16-31.

2. Cruz-Jentoft AJ, Landi F, Schneider SM, et al. (2014) Prevalence of and interventions for sarcopenia in ageing adults: a systematic review. Report of the International Sarcopenia Initiative (EWGSOP and IWGS). Age Ageing 43, 748-759.

3. Morley JE, Anker SD \& von Haehling S (2014) Prevalence, incidence, and clinical impact of sarcopenia: facts, numbers, and epidemiology-update 2014. J Cachexia Sarcopenia Muscle 5 , 253-259.

4. Cruz-Jentoft AJ, Landi F, Topinková E, et al. (2010) Understanding sarcopenia as a geriatric syndrome. Curr Opin Clin Nutr Metab Care 13, 1-7.

5. Cao L \& Morley JE (2016) Sarcopenia is recognized as an independent condition by an International Classification of Disease, Tenth Revision, Clinical Modification (ICD-10-CM) Code. J Am Med Dir Assoc 17, 675-677.

6. Norman K \& Otten L (2018) Financial impact of sarcopenia or low muscle mass - a short review. Clin Nutr 38, 1489-1495.

7. Cawthon PM, Fox KM, Gandra SR, et al. (2009) Do muscle mass, muscle density, strength, and physical function similarly influence risk of hospitalization in older adults? J Am Geriatr Soc 57, 1411-1419.

8. Toss F, Wiklund P, Nordstrom P, et al. (2012) Body composition and mortality risk in later life. Age Ageing 41, 677-681.

9. Rizzoli R, Reginster J-Y, Arnal J-F, et al. (2013) Quality of life in sarcopenia and frailty. Calcif Tissue Int 93, 101-120.

10. Antunes AC, Araújo DA, Veríssimo MT, et al. (2017) Sarcopenia and hospitalisation costs in older adults: a cross-sectional study: sarcopenia and hospitalization costs in older adults. Nutr Diet 74, 46-50.

11. Malafarina V, Uriz-Otano F, Iniesta R, et al. (2013) Effectiveness of nutritional supplementation on muscle mass in treatment of sarcopenia in old age: a systematic review. J Am Med Dir Assoc 14, 10-17.

12. Komar B, Schwingshackl L \& Hoffmann G (2015) Effects of leucine-rich protein supplements on anthropometric parameter and muscle strength in the elderly: a systematic review and meta-analysis. I Nutr Health Aging 19, 437-446.

13. Cheng H, Kong J, Underwood C, et al. (2018) Systematic review and meta-analysis of the effect of protein and amino acid supplements in older adults with acute or chronic conditions. $\mathrm{BrJ}$ Nutr 119, 527-542.

14. Cermak NM, Res PT, de Groot LC, et al. (2012) Protein supplementation augments the adaptive response of skeletal muscle to resistance-type exercise training: a meta-analysis. Am J Clin Nutr 96, 1454-1464.

15. Thomas DK, Quinn MA, Saunders DH, et al. (2016) Protein supplementation does not significantly augment the effects of resistance exercise training in older adults: a systematic review. J Am Med Dir Assoc 17, 959.e1-959.e9.
16. Gade J, Pedersen RJ \& Beck AM (2018) Effect of protein or essential amino acid supplementation during prolonged resistance exercise training in older adults on body composition, muscle strength, and physical performance parameters: a systematic review. Rehabil Process Outcome 7, 117957 271876576.

17. Morton RW, Murphy KT, McKellar SR, et al. (2017) A systematic review, meta-analysis and meta-regression of the effect of protein supplementation on resistance training-induced gains in muscle mass and strength in healthy adults. Br J Sports Med 52, 376-384.

18. Finger D, Goltz FR, Umpierre D, et al. (2015) Effects of protein supplementation in older adults undergoing resistance training: a systematic review and meta-analysis. Sports Med 45, 245-255.

19. Liao C-D, Lee P-H, Hsiao D-J, et al. (2018) Effects of protein supplementation combined with exercise intervention on frailty indices, body composition, and physical function in frail older adults. Nutrients 10, 1916.

20. The IOF-ESCEO Sarcopenia Working Group, Beaudart C, Dawson A, et al. (2017) Nutrition and physical activity in the prevention and treatment of sarcopenia: systematic review. Osteoporos Int 28, 1817-1833.

21. Wright J \& Baldwin C (2018) Oral nutritional support with or without exercise in the management of malnutrition in nutritionally vulnerable older people: a systematic review and meta-analysis. Clin Nutr 37, 1879-1891.

22. Robinson S, Denison H, Cooper C, et al. (2015) Prevention and optimal management of sarcopenia: a review of combined exercise and nutrition interventions to improve muscle outcomes in older people. Clin Interv Aging 10, 859-869.

23. Hidayat K, Chen G-C, Wang Y, et al. (2018) Effects of milk proteins supplementation in older adults undergoing resistance training: a meta-analysis of randomized control trials. J Nutr Health Aging 22, 237-245.

24. Beaudart C, Zaaria M, Pasleau F, et al. (2017) Health outcomes of sarcopenia: a systematic review and meta-analysis. PLOS ONE 12, e0169548.

25. Bauer J, Biolo G, Cederholm T, et al. (2013) Evidence-based recommendations for optimal dietary protein intake in older people: a position paper from the PROT-AGE study group. J Am Med Dir Assoc 14, 542-559.

26. Campbell WW \& Leidy HJ (2007) Dietary protein and resistance training effects on muscle and body composition in older persons. J Am Coll Nutr 26, 696S-703S.

27. Gade J, Beck AM, Bitz C, et al. (2018) Protein-enriched, milkbased supplement to counteract sarcopenia in acutely ill geriatric patients offered resistance exercise training during and after hospitalisation: study protocol for a randomised, double-blind, multicentre trial. BMJ Open 8, e019210.

28. National Board of Health, Denmark (2010) Recommendations on vitamin D intake. https://www.sst.dk/da/rationel-farmakoterapi/ maanedsbladet/2010/maanedsblad_nr_6_juni_2010/forebygge lse diagnostik_og behandling af_d-vitaminmangel

29. Djernes J, Kvist E, Olesen F, et al. (2004) Validation of a Danish translation of Geriatric Depression Scale-15 as a screening tool for depression among frail elderly living at home. Ugeskr Laeger 166, 905-909.

30. Kondrup J (2003) Nutritional risk screening (NRS 2002): a new method based on an analysis of controlled clinical trials. Clin Nutr 22, 321-336.

31. Jones CJ, Rikli RE \& Beam WC (1999) A 30-s chair-stand test as a measure of lower body strength in community-residing older adults. Res Q Exerc Sport 70, 113-119. 
32. Rikli RE \& Jones CJ (2001) Senior Fitness Test Manual, 2nd ed. Champaign, IL: Human Kinetics.

33. Roberts HC, Denison HJ, Martin HJ, et al. (2011) A review of the measurement of grip strength in clinical and epidemiological studies: towards a standardised approach. Age Ageing 40, 423-429.

34. Shah S, Vanclay F \& Cooper B (1989) Improving the sensitivity of the Barthel Index for stroke rehabilitation. J Clin Epidemiol 42, 703-709.

35. Maribo T, Lauritsen JM, Waehrens E, et al. (2006) Barthel Index for evaluation of function: a Danish consensus on its use. Ugeskr Laeg 168, 2790-2792.

36. de Morton NA, Davidson M \& Keating JL (2008) The De Morton Mobility Index (DEMMI): an essential health index for an ageing world. Health Qual Life Outcomes 6, 63.

37. Folstein MF, Folstein SE \& McHugh PR (1975) Mini-mental state. J Psychiatr Res 12, 189-198.

38. EuroQol Group (1990) EuroQol - a new facility for the measurement of health-related quality of life. Health Policy 16, 199-208.

39. Nelson M, Black AE, Morris JA, et al. (1989) Between- and within-subject variation in nutrient intake from infancy to old age: estimating the number of days required to rank dietary intakes with desired precision. Am J Clin Nutr 50, 155-167.

40. Nielsen T, Biltoft-Jensen A \& Ygil K (2011) Development of Picture Series for The National Survey of the Danes' Dietary Habits and Physical Activity 2011. Lyngby, Denmark: Technical University of Denmark (DTU), Food Institute, Department of Nutrition.

41. Saltin B \& Grimby G (1968) Physiological analysis of middleaged and old former athletes: comparison with still active athletes of the same ages. Circulation 38, 1104-1115.

42. Wright AA, Cook CE, Baxter GD, et al. (2011) A Comparison of 3 methodological approaches to defining major clinically important improvement of 4 performance measures in patients with hip osteoarthritis. J Orthop Sports Phys Ther 41, 319-327.

43. Pedersen MM, Petersen J, Bean JF, et al. (2015) Feasibility of progressive sit-to-stand training among older hospitalized patients. PeerJ 3, e1500.

44. Vestergaard M \& Beyer N (2009) Stol på idrcet 2005-2008. Evaluation report 1, Frederecia, Denmark: Danish Workers' Sports Association.

45. Chodzko-Zajko WJ, Proctor DN, Fiatarone Singh MA, et al. (2009) Exercise and physical activity for older adults. Med Sci Sports \& Exerc 41, 1510-1530.

46. The Steering Committee for the Danish Clinical Registries and The Regional Clinical Quality Development Program (2016) The National Database for Geriatrics, annual report; 2016. Denmark: The Danish Clinical Registries.

47. The National Health Data Board (2016) Elderly Medical Patients' Contact with the Regional Health Service and the Municipal Care. Denmark: Department of Health Analysis and Pharmaceutical Statistics.

48. Neel Jakobsen H, Denmark, National Board of Health, et al. (2007) Follow-Up Home Visits at Elderly Patients After Discharge from Hospital - A Health Technology Assessment. National Board of Health.

49. Deutz NEP, Bauer JM, Barazzoni R, et al. (2014) Protein intake and exercise for optimal muscle function with aging: recommendations from the ESPEN Expert Group. Clin Nutr 33, 929-936.
50. The Nordic Council of Ministers (2014) Nordic Nutrition Recommendations 2012: Integrating Nutrition and Physical Activity, 5th ed. Copenhagen, Denmark: Norden.

51. Symons TB, Sheffield-Moore M, Wolfe RR, et al. (2009) A moderate serving of high-quality protein maximally stimulates skeletal muscle protein synthesis in young and elderly subjects. J Am Diet Assoc 109, 1582-1586.

52. Moore DR, Churchward-Venne TA, Witard O, et al. (2015) Protein ingestion to stimulate myofibrillar protein synthesis requires greater relative protein intakes in healthy older versus younger men. J Gerontol A Biol Sci Med Sci 70, 57-62.

53. Pennings B, Groen B, de Lange A, et al. (2012) Amino acid absorption and subsequent muscle protein accretion following graded intakes of whey protein in elderly men. Am J Physiol Endocrinol Metab 302, E992-E999.

54. Deutz NE \& Wolfe RR (2013) Is there a maximal anabolic response to protein intake with a meal? Clin Nutr 32, 309-313.

55. Volpi E, Campbell WW, Dwyer JT, et al. (2013) Is the optimal level of protein intake for older adults greater than the recommended dietary allowance? J Gerontol A Biol Sci Med Sci 68 , 677-681.

56. Paddon-Jones D \& Leidy H (2014) Dietary protein and muscle in older persons. Curr Opin Clin Nutr Metab Care 17, 5-11.

57. Burd NA, West DWD, Moore DR, et al. (2011) Enhanced amino acid sensitivity of myofibrillar protein synthesis persists for up to $24 \mathrm{~h}$ after resistance exercise in young men. J Nutr 141, 568573.

58. Niccoli S, Kolobov A, Bon T, et al. (2017) Whey protein supplementation improves rehabilitation outcomes in hospitalized geriatric patients: a double blinded, randomized controlled trial. J Nutr Gerontol Geriatr 36, 149-165.

59. Pasiakos SM, McLellan TM \& Lieberman HR (2015) The effects of protein supplements on muscle mass, strength, and aerobic and anaerobic power in healthy adults: a systematic review. Sports Med 45, 111-131.

60. Naclerio F \& Larumbe-Zabala E (2016) Effects of whey protein alone or as part of a multi-ingredient formulation on strength, fat-free mass, or lean body mass in resistance-trained individuals: a meta-analysis Sports Med 46, 125-137.

61. Shils ME \& Shike M (editors) (2006) Modern Nutrition in Health and Disease, 10th ed. Philadelphia, PA: Lippincott Williams \& Wilkins.

62. Dominguez LJ \& Barbagallo M (2013) Perspective: protein supplementation in frail older persons: often necessary but not always sufficient. J Am Med Dir Assoc 14, 72-73.

63. Poppitt S, Swann D, Black A, et al. (1998) Assessment of selective under-reporting of food intake by both obese and nonobese women in a metabolic facility. Int J Obes Relat Metab Disord 22, 303-311.

64. Vasse E, Beelen J, de Roos NM, et al. (2018) Protein intake in hospitalized older people with and without increased risk of malnutrition. Eur J Clin Nutr 72, 917-919.

65. Trabal J, Forga M, Leyes P, et al. (2015) Effects of free leucine supplementation and resistance training on muscle strength and functional status in older adults: a randomized controlled trial. Clin Interv Aging 10, 713-723.

66. Maltais ML, Ladouceur JP \& Dionne IJ (2016) The Effect of resistance training and different sources of postexercise protein supplementation on muscle mass and physical capacity in sarcopenic elderly men. J Strength Cond Res 30, 1680-1687. 